\title{
Creating a multifunctional composite stator slot material system to enable high power density electric machines for electrified aircraft applications
}

\author{
Andrew A. Woodworth and Ralph Jansen \\ NASA Glenn Research Center
}

\author{
Kirsten Duffy \\ University of Toledo
}

Paria Naghipour and Euy-Sik Shin

Ohio Aerospace Institute 


\section{Electric Machine Motivation: STARC-ABL}

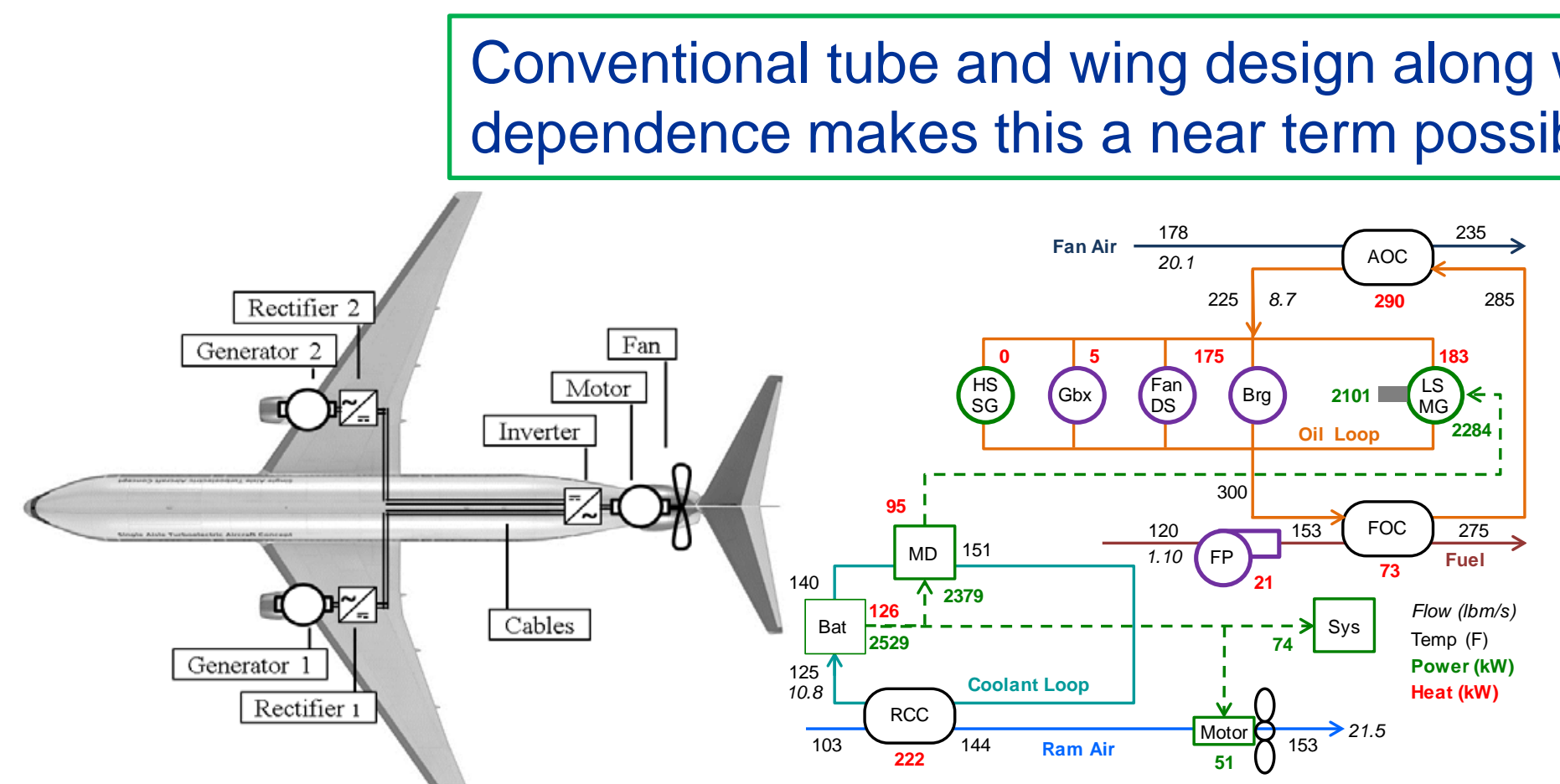

\begin{tabular}{|c||c||c||c|}
\cline { 2 - 4 } \multicolumn{1}{c|}{} & \multicolumn{3}{c|}{ Max Temp } \\
\hline Cooling Loop & ${ }^{\circ} \mathrm{C}$ & ${ }^{\circ} \mathrm{F}$ & $\mathrm{K}$ \\
\hline Coolant & 60 & 140 & 333 \\
\hline Oil & 135 & 275 & 408 \\
\hline
\end{tabular}

UTRC Concept for HGEP Thermal Management

\section{Electrical Machines}

- Two 1.4 MW generators mounted near turbines

- $\quad$ One 2.6 MW motor driving tail cone thruster

\section{Geared Turbofan}

- HP Spool = ? rpm

- $\quad$ LP Spool $=6800 \mathrm{rpm}$ (generator connects here)
Tailcone Thruster

- Fan $=2514 \mathrm{rpm}$

- Diameter $=80.2 "$

- Hub/Tip Ratio $=0.3$

- Hub Diameter = 24.1"
High Power Density Electric Machine

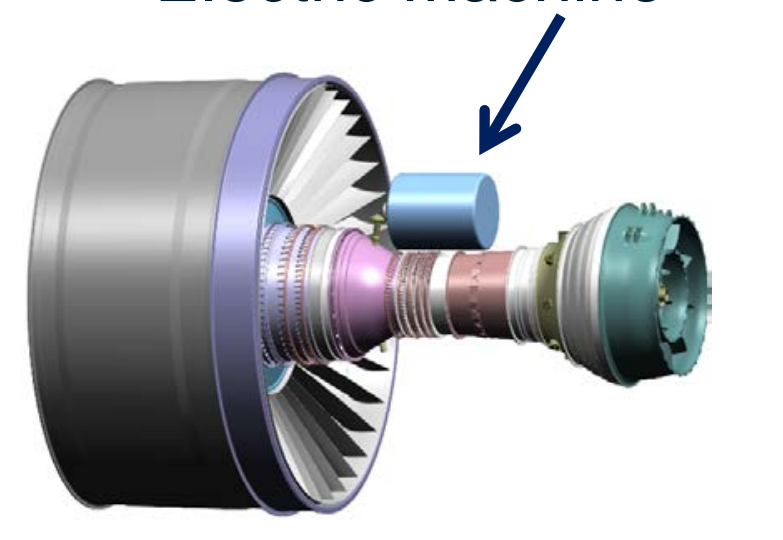

UTRC concept for Hybrid Geared Turbofan 


\section{Electric Machine Motivation: NASA Efforts}

- Internal NASA motor development

- Target >98\% Efficiency Stretch Goal 99\%

- $16 \mathrm{~kW} / \mathrm{kg}$

- $1.46 \mathrm{MW}$

- External NASA funded motor development

- $>13 \mathrm{~kW} / \mathrm{kg}$

- $>1 \mathrm{MW}$

- >96\% Efficient

- Teams at UIUC \& OSU

- All teams have chosen Litz wire or form wound conductors to meet their goals

- High power densities $=$ higher temperatures $=$ more loss $\left(10^{\circ} \mathrm{C}\right.$ increase in temperature is a $3.9 \%$ increase in resistive loss)

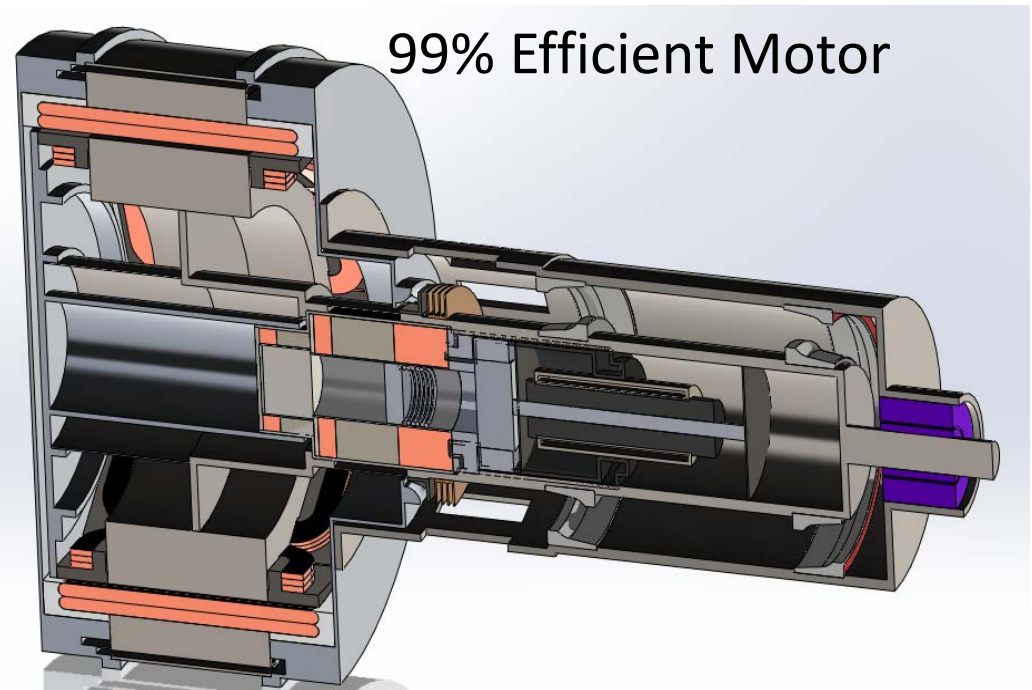

Motor Description

Rotor $\left\{\begin{array}{c}\text { Carbon Fiber Retaining Ring } \\ \text { Titanium Shell } \\ \text { Permanent Magnet }\end{array}\right]$

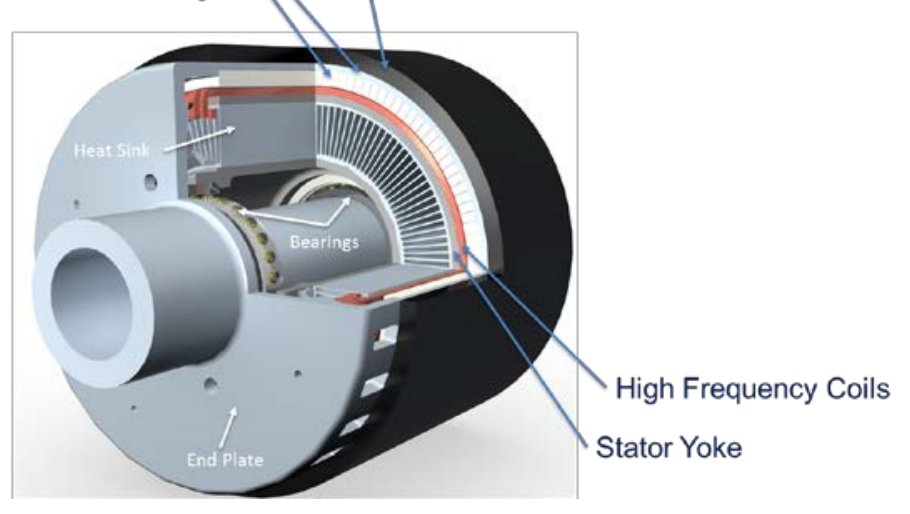

NASA NRA: High Power Density Motor Under Development by Professor Haran's Group University of Illinois Urbana-Champaign. Contracting Officer Representative Andrew Provenza, NASA Glenn Research Center 


\section{Litz Wire}

nylon serve

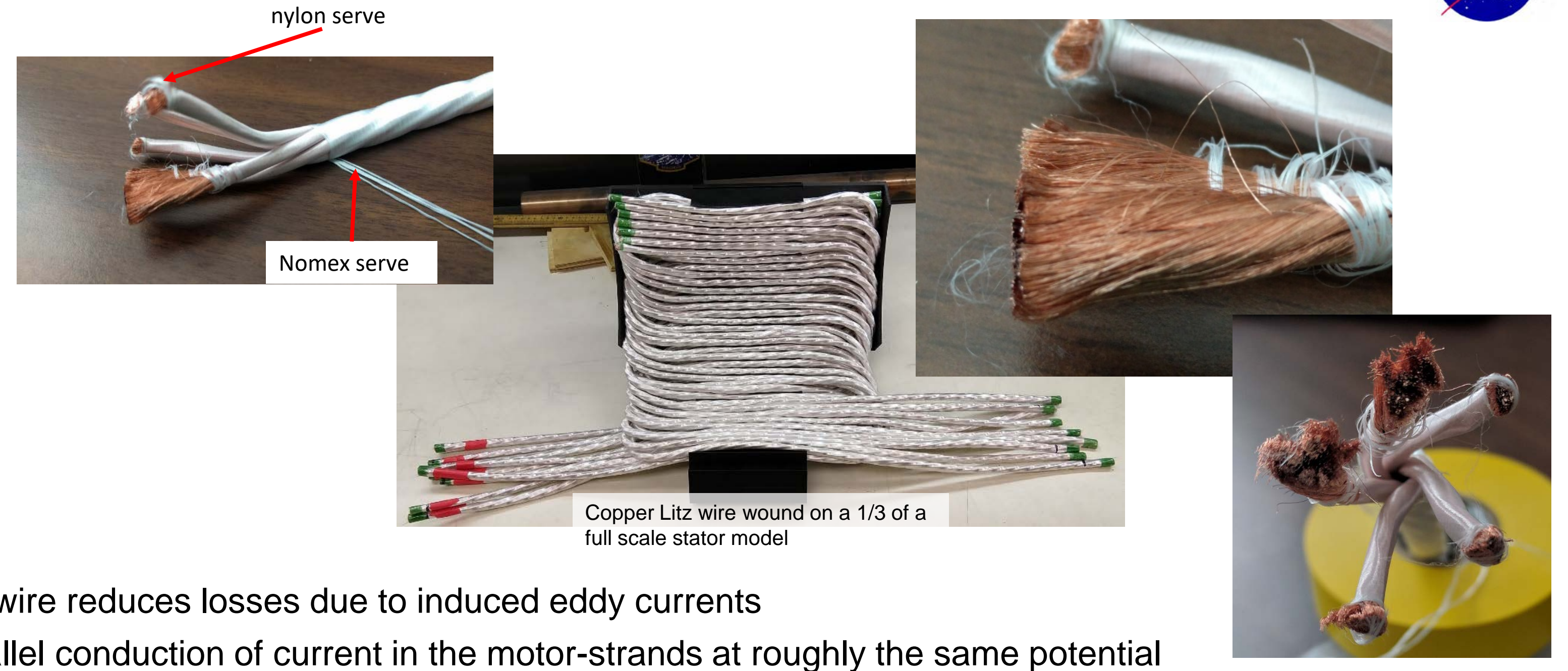

- Parallel conduction of current in the motor-strands at roughly the same potential
- Standard magnet wire electrical insulation on each strand is a significant over design
- Litz wire offers a unique design space for new material solutions

-Parallel conduction of current in the motor-strands at roughly the
- Standard magnet wire electrical insulation on each strand is
- Litz wire offers a unique design space for new material solutions

- Litz wire reduces losses due to induced eddy currents 
HV Insulation

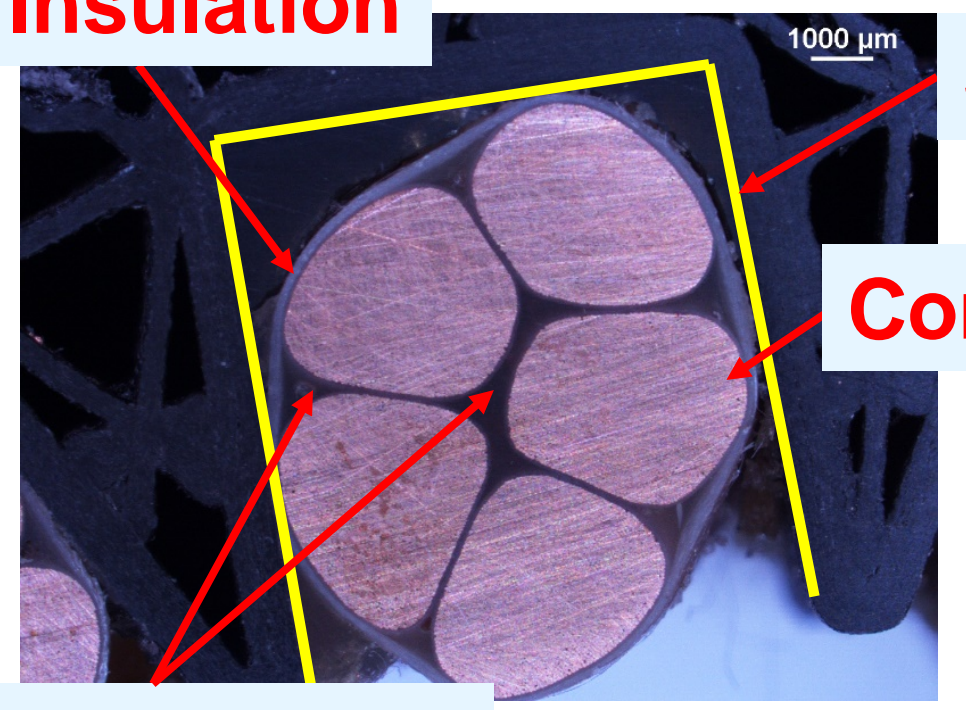

Conductor

Potting Material

\section{Inside a Stator Slot}

Slot

- soft magnetic material

Wire insulation

- electric isolation, polyimde $\sim 0.1 \mathrm{~W} / \mathrm{m}-\mathrm{K}$

HV Insulation

- electrical isolation, polyamide or mica $(1-2 \mathrm{~W} / \mathrm{m}-\mathrm{K})$

Potting material

- mechanical stabilization/thermal management*

- epoxy $\sim 2 \mathrm{~W} / \mathrm{m}-\mathrm{K}$ (with some exceptions)
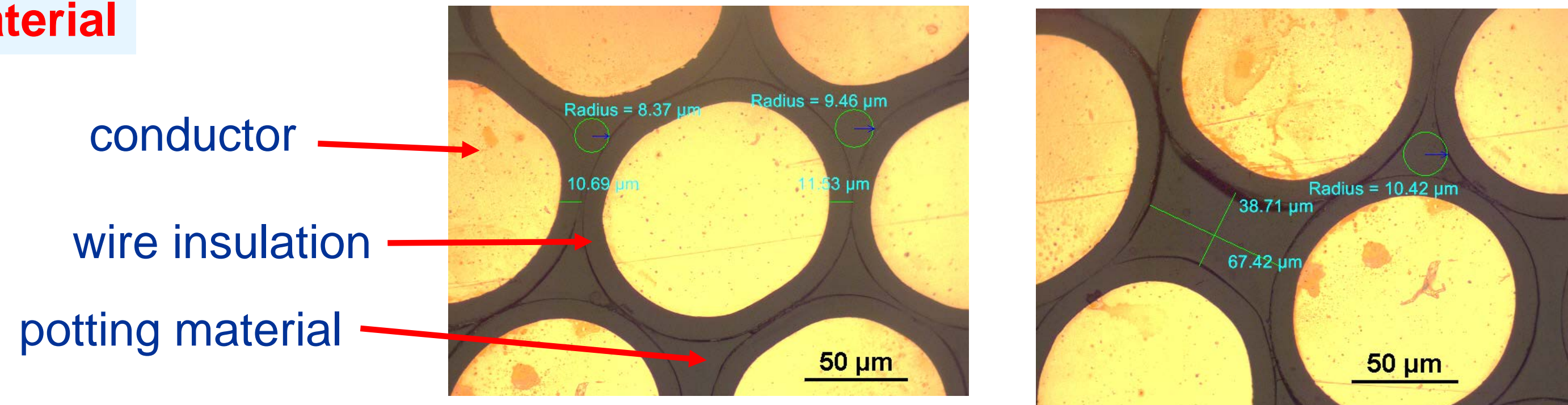

Potted AWG 38 (101 micrometer diameter) with a heavy build polyimde insulation 


\section{Thermal Effects: Potting Material vs. Wire Insulation}

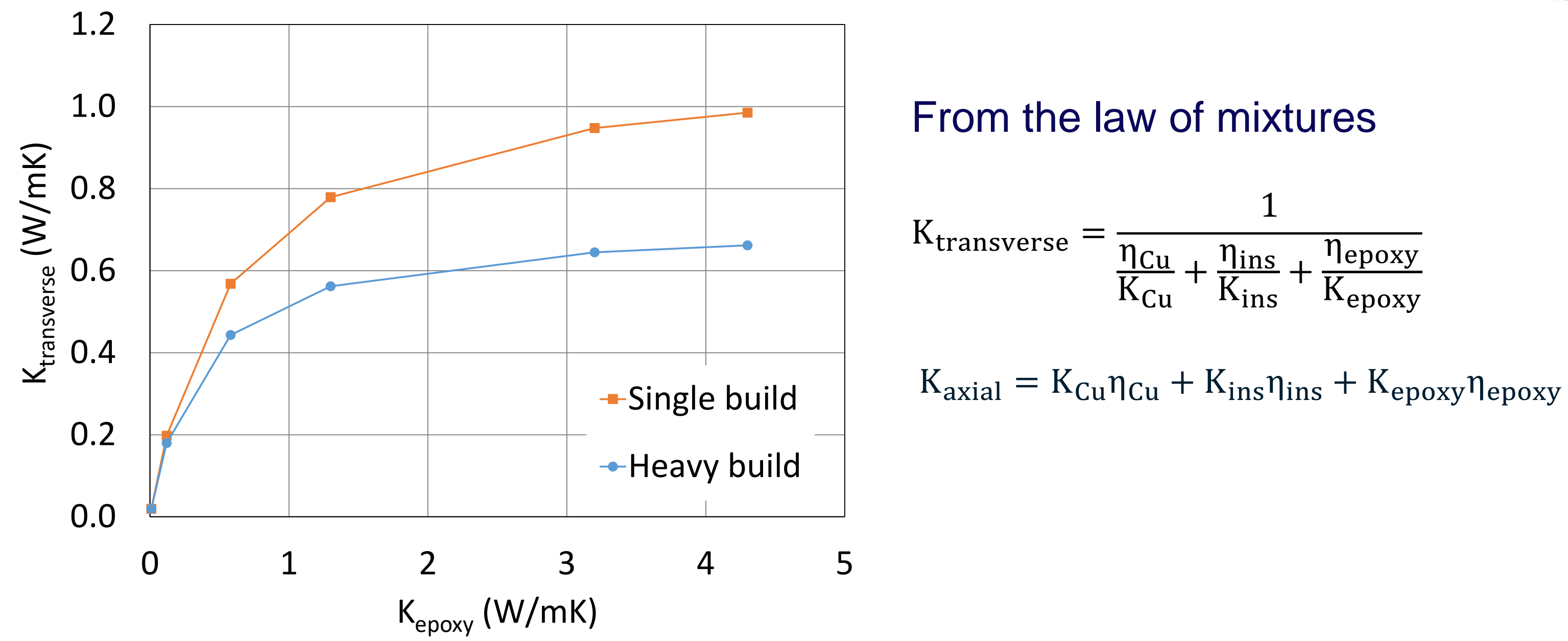

- Increasing the thermal conductivity of the potting material (epoxy) has a significant effect on thermal conductivity

- Wire insulation is a significant thermal choke

- Does ins the traditional wire insulation necessary with Litz wire-could it be replaced with the potting material 


\section{Finite Element Analysis (FEA) of the High Voltage Insulation}

High voltage insulation breakdown ( $>2 x$ operating voltage of the motor) is necessary between phases in a stator slot and between the conductor and back iron

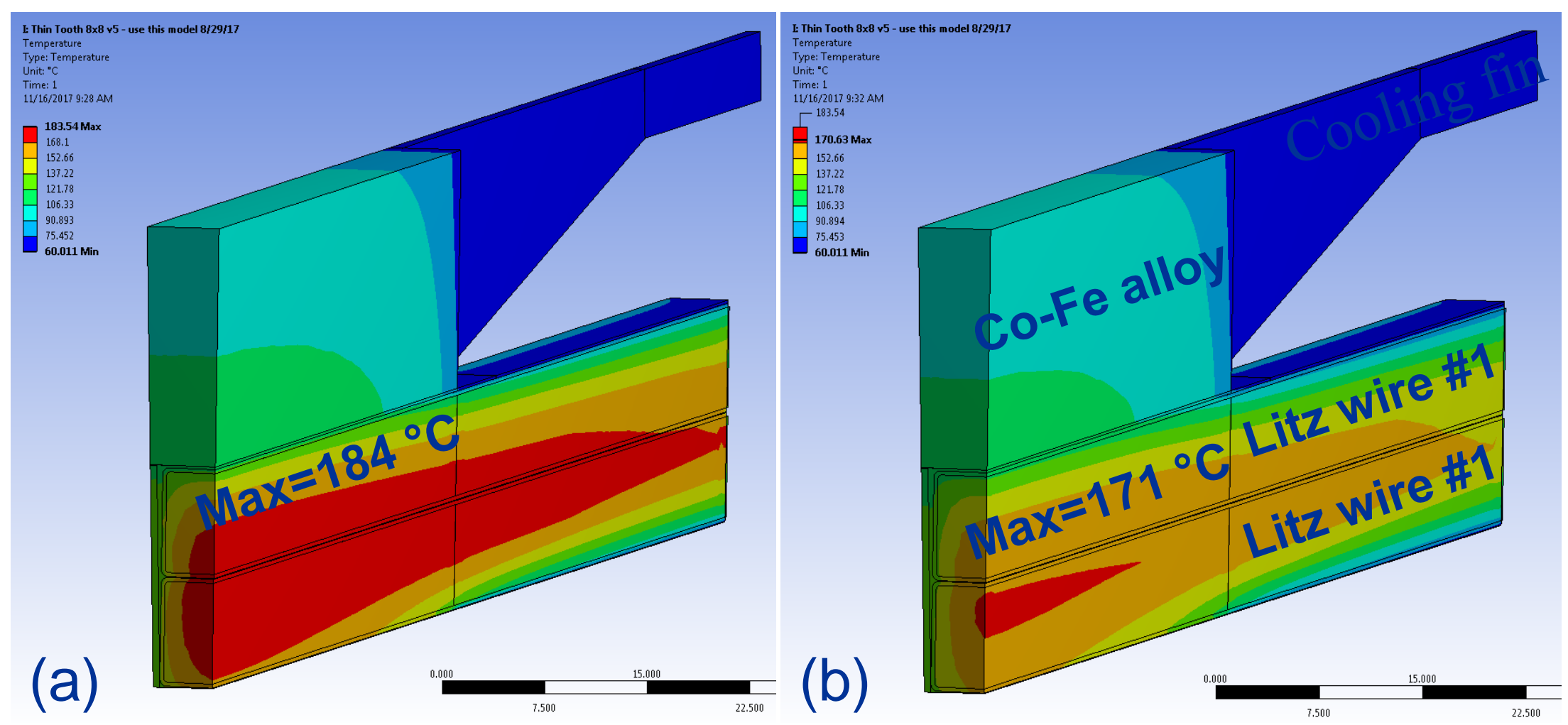

FEA of a theoretical motor slot. High voltage insulation wraps each Litz wire. High voltage insulation thermal conductivity (a) $0.12 \mathrm{~W} / \mathrm{m}-\mathrm{K}$ and (b) $0.24 \mathrm{~W} / \mathrm{m}-\mathrm{K}$ 


\section{High Fidelity Generalized Method of Cells (HFGMC)}

Provides a $10 x$ increase in computational speed while minting most of the accuracy of FEA

Makes computations of large number of the repeated structures possible
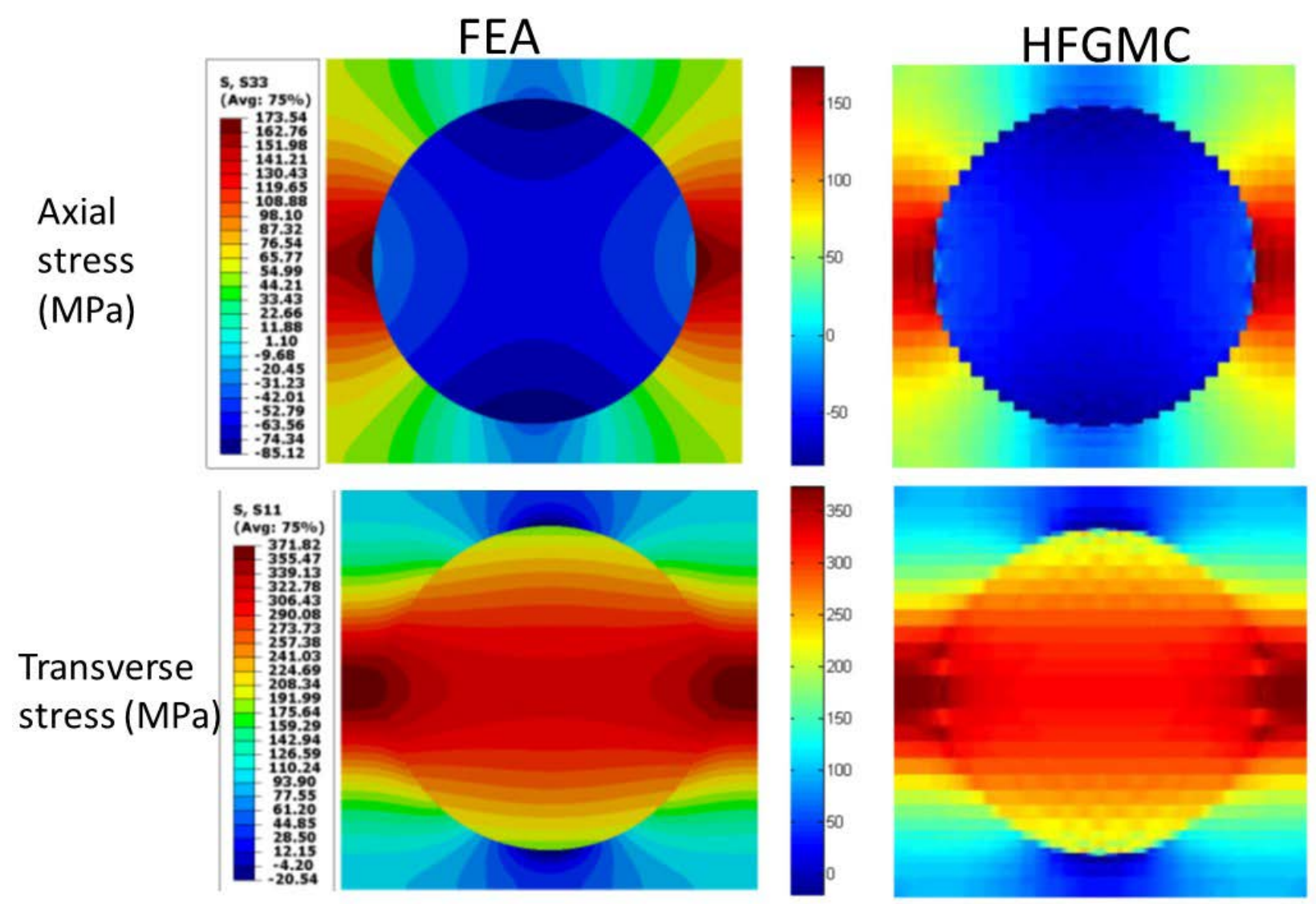


\section{Preliminary Micro Thermal Modeling Results}

Hexagonal

Conductor $~-55-60 \%$ Insulator $\sim 20 \%-30 \%$

Potting material $15-20 \%$

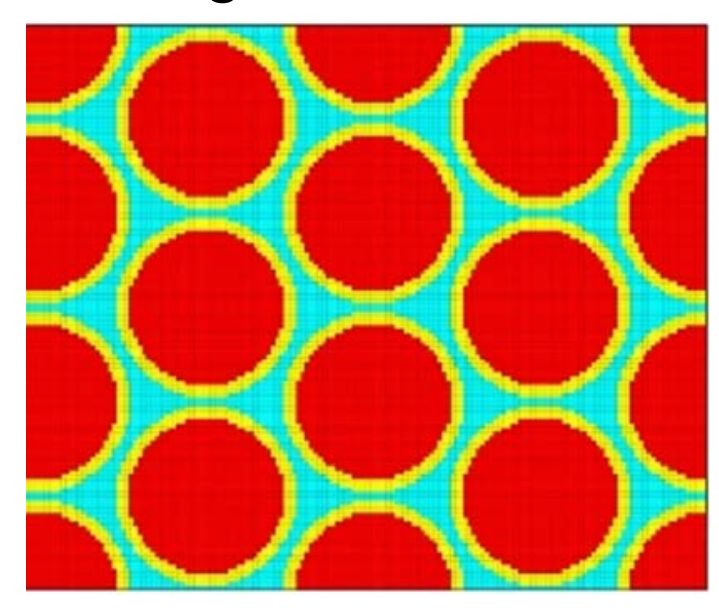

$\mathrm{K}_{\|}=380 \mathrm{~W} / \mathrm{m}-\mathrm{K}$

$\mathrm{K}_{\perp_{22}}=0.79750 \mathrm{~W} / \mathrm{m}-\mathrm{K}$

$\mathrm{K}_{\perp_{33}}=0.79529 \mathrm{~W} / \mathrm{m}-\mathrm{K}$
Square

$<<$ Place holder for pickling factors $>>$

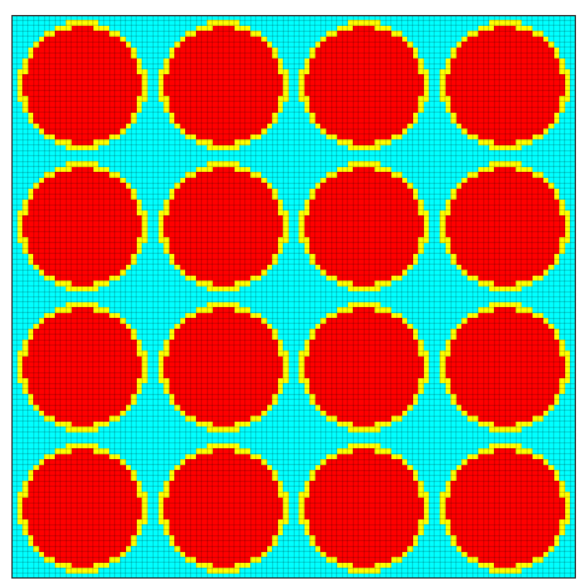

Square

$\mathrm{K}_{\|}=290 \mathrm{~W} / \mathrm{m}-\mathrm{K}$

$\mathrm{K}_{\perp_{22}}=0.86730 \mathrm{~W} / \mathrm{m}-\mathrm{K}$

$\mathrm{K}_{\perp_{33}}=0.86730 \mathrm{~W} / \mathrm{m}-\mathrm{K}$

Random I and II Conductor: $45-50 \%$ Insulator: 20\%-30\% Potting material: $25-30 \%$

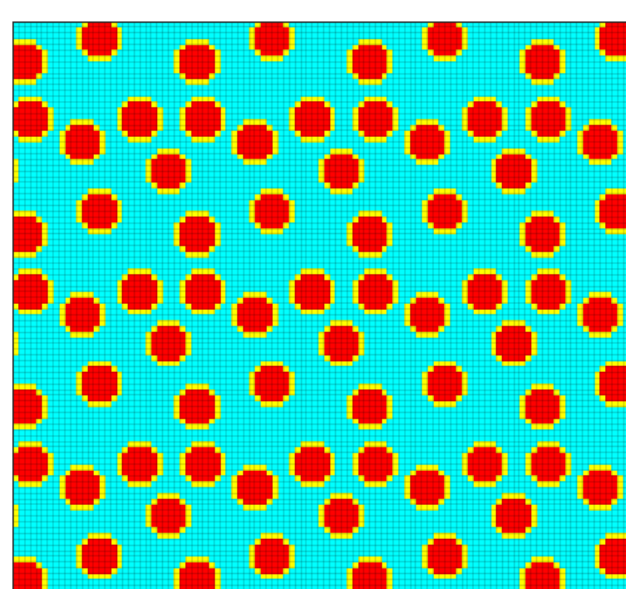

Random-I

$\mathrm{K}_{\|}=240 \mathrm{~W} / \mathrm{m}-\mathrm{K}$

$\mathrm{K}_{\perp_{22}}=0.442 \mathrm{~W} / \mathrm{m}-\mathrm{K}$

$\mathrm{K}_{\perp_{33}}=0.421 \mathrm{~W} / \mathrm{m}-\mathrm{K}$

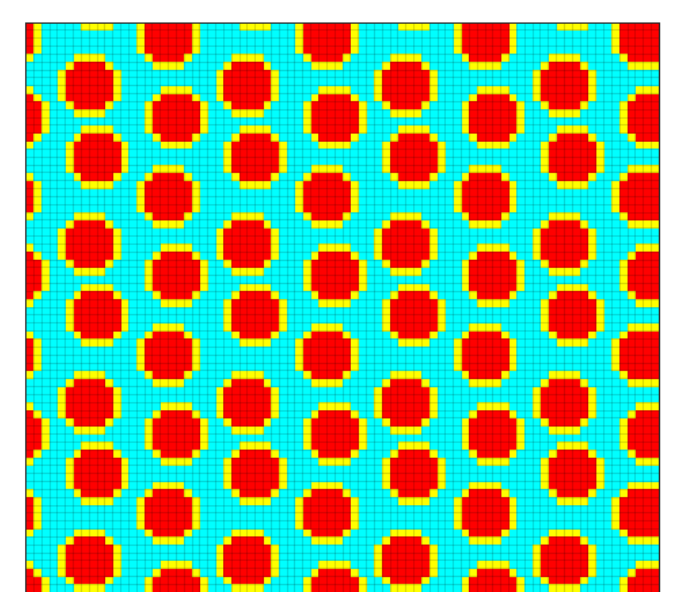

Random-II

$\mathrm{K}_{\|}=255 \mathrm{~W} / \mathrm{m}-\mathrm{K}$

$\mathrm{K}_{\perp_{22}}=0.528 \mathrm{~W} / \mathrm{m}-\mathrm{K}$

$\mathrm{K}_{\perp_{33}}=0.524 \mathrm{~W} / \mathrm{m}-\mathrm{K}$ 


\section{Summary \& Conclusions}

- Conceptualizing the insulation materials systems as composite is the key gaining to multi-functionality

- Electrical

- Thermal

- Mechanical

- Composite approach provides modest, achievable goals can be set. thermal conductivities for

- potting materials $>1 \mathrm{~W} / \mathrm{m}-\mathrm{K}$, and

- High Voltage Insulation $\sim 0.5 \mathrm{~W}-\mathrm{m} / \mathrm{K}$

- possibly replacing or eliminating the insulation material on the Litz wire. These

- goals are backed up by finite element modeling.

- Higher fidelity micro thermal modeling along with testing and model validation will bring more clarity to how the physical system behaves and will also refine the material development goals. 


\section{Acknowledgments}

> Advanced Air Transport Technology Project, Hybrid Gas Electric Propulsion Program - Amy Jankovsky and Cheryl Bowman

$>$ Transformative Tool and Technology Program - Janet Hurst

Electric Machine Insulation Development Team

- Tiffany Williams

- Maricela Lizcano

- Daniel Scheiman

- Marisabel Kelly

- Kathy Chuang
99\% Efficient Motor Development Team

- Yaritza DeJesus - Arcer

- Paul Passe

- Sean McCormick

- Pete Kascak

- Justin Scheidler

- Ryan Edwards

- Erik Stalcup

- Jarred Wilhite 
Thank you! 